\title{
Hydrothermal Preparation and Characterization of Co-based Layered Double Hydroxide and their Catalytic Activity
}

\author{
A.I. Abd-Elhamid ${ }^{*}$, Hisham M.A. Soliman ${ }^{1}$, H. F. Aly ${ }^{2}$ \\ ${ }^{1}$ Advanced Technology and New Materials Research Institute, City for Scientific Research and Technology \\ Applications, P. O. Box 21934, SRTA, Egypt \\ ${ }^{2}$ Hot Laboratories Center, Atomic Energy Authority, Nasr 13759, Egypt \\ Email: ahm_ch_ibr@yahoo.com
}

\begin{abstract}
In this report an efficient catalyst was prepared by hydrothermal route to produce $\mathrm{Co}-\mathrm{Al}$ layered double hydroxide nanosheets (LDH-NS) (less active material), followed by alkali treatment to prepare the more active material (A-LDH). The scanning electron microscope (SEM), Fourier transform infrared spectroscopy (FTIR), X-ray diffraction (XRD) and Energy-dispersive X-ray spectroscopy (EDX) techniques were used to determine the morphological and chemical properties, chemical structure and the elemental analysis of both layered double hydroxide nanosheets LDH-NS and alkali treated layered double hydroxide nanosheets (A-LDH). Moreover, the both samples LDHNS and A-LDH show a significantly catalytic behavior towards the degradation of crystal violet (CV) dye in the presence of $\mathrm{H}_{2} \mathrm{O}_{2}$ as assisting agent. However, the catalytic efficiency for both samples LDH-NS and A-LDH is highly reduced in the absence of the oxidizing agent $\left(\mathrm{H}_{2} \mathrm{O}_{2}\right)$. The apparent rate constant of the catalytic degradation reaction was preformed from the first order kinetic model.
\end{abstract}

Keyword: Layered double hydroxide; alkali treatment; catalytic degradation; CV-dye; water treatment.

\section{Introduction}

Dye stuff is one of the most effluents that discharge from the industry's activity, such as plastics and textiles. The presence of the dye in water makes it colored and undesirable even at low concentration [1]. Moreover, the aquatic life is highly affected by the presence of the dye, where it retards the light penetration and thus reduces the photosynthesis of aquatic plants which destroys aquatic ecosystems [2]. Hence, it is very important to investigate an effective technique to remove the dyes from the waste water, such as photocatalytic degradation [3], adsorption on activated carbon [4], bacterial action [5], electrochemical degradation [6] and catalytic degradation [7]. Heterogeneous catalytic reaction of the organic pollutants in wastewater appears to be a more effective, economically feasible process for destructing a variety of hazardous pollutants and providing complete oxidation [8]. Layered double hydroxides (LDH) are classified as 2D ionic solids, which are found in nature as mineral, characterized by a layered structure with stiometeric formula $\left.\left[\mathrm{M}_{1-\mathrm{x}}^{2+} \mathrm{M}_{\mathrm{x}}^{3+}(\mathrm{OH})_{2}\right]^{\mathrm{x+}}\left(\mathrm{A}^{\mathrm{n}-}\right)_{\mathrm{n}}^{\mathrm{x}} \cdot \mathrm{mH}_{2} \mathrm{O}\right]$, where $\mathrm{M}^{2+}$ and $\mathrm{M}^{3+}$ are the divalent and trivalent metal cations, respectively, and $\mathrm{A}^{\mathrm{n}-}$ is an interlayer anion [9]. The substitution of a portion of the divalent metal cation with trivalent cation, the brucite-like layer gains a positive charge, this positive charge equilibrated by an interlayer anion [10]. The water molecules which present in the interlayer space, form with layers ${ }^{-} \mathrm{OH}$ and/or the interlayer anions $\mathrm{H}$-bond. Because of the electrostatic interaction and H-bonds, the $\mathrm{LDH}$ formed in the layer structure [10]. Due to its physicochemical properties, LDH owns wide applications including drug delivery carriers [11], Biosensors [12], water treatment agents [13], Catalysts [14], supercapacitors [15]. Hence, the preparation of CoAlLDH proceeded using several routes such as; co-precipitation [16], microwave-assisted reflux method [17], hydrothermal synthesis method [18] and electrodeposition [19].

In addition, owing to their layered structure, high anion-exchange capacity, their relatively low cost, high redox activity, and environmentally friendly nature [20], LDHs become potential materials in different applications such as catalysts, photo-catalysts, catalyst supports, adsorbents, anion exchangers, medicines, flame-retardation, polymer stabilization, electrochemistry, bonding materials, and so on [21]. 
In this work, we reported the activation of $\mathrm{Co}-\mathrm{Al}$ layered double hydroxide nanosheets through basic treatment and study its catalytic efficiency for CV degradation in presence and absence of $\mathrm{H}_{2} \mathrm{O}_{2}$.

\section{Experimental}

\subsection{Materials}

Cobalt acetate $\left(\mathrm{Co}(\mathrm{ac})_{2} \bullet 6 \mathrm{H}_{2} \mathrm{O}\right.$, Spectrum Chemical, 98\%), Aluminum nitrate $\left(\mathrm{Al}\left(\mathrm{NO}_{3}\right)_{3}, \mathrm{BDH}\right.$ chemicals, 97\%), Urea $\left(\mathrm{CO}\left(\mathrm{NH}_{2}\right)_{2}\right.$, Center drug house, $\left.99 \%\right)$, Sodium hydroxide (NaOH, Riede-deHaë, $99 \%)$, Crystal violet $\left(\mathrm{C}_{25} \mathrm{H}_{30} \mathrm{~N}_{3} \mathrm{Cl}\right.$, Sigma Aldrich, A C S reagent, $\geqslant 90.0 \%$ anhydrous basis $)$

\subsection{Synthesis of Catalyst}

In a typical experiment, Teflon-lined stainless-steel autoclave, which contains a homogeneous solution of $\mathrm{Co}(\mathrm{ac})_{2} \bullet 6 \mathrm{H}_{2} \mathrm{O}(0.37 \mathrm{~g}), \mathrm{Al}\left(\mathrm{NO}_{3}\right)_{3}(0.25 \mathrm{~g}), \mathrm{CO}\left(\mathrm{NH}_{2}\right)_{2}(0.5 \mathrm{~g})$ and $20 \mathrm{ml}$ deionized water. Afterwards, the autoclave was sealed and maintained at $150{ }^{\circ} \mathrm{C}$ for 24 hours. After that, it was left to cool down to the room temperature. The obtained pink color precipitate was washed with deionized water and dried at 70 ${ }^{\circ} \mathrm{C}$. The resulting solid was labeled as CoAl layered double hydroxide nanosheets (LDH-NS).

The next is a synthesis of activated layered double hydroxide (A-LDH) by treating (LDH-NS) with alkali media. The pink sample was immersed in $0.5 \mathrm{M}$ sodium hydroxide solution for 48 hours, at room temperature. The color of the sample changes to brown.

\subsection{Characterization}

The characterization of the prepared LDH and A-LDH was carried out by Scanning Electron Microscope (SEM) (JSM-636 OLA, Jeol, Japan.), Fourier Transmission Infra-Red Spectroscopy (FT-IR) (8400s, Shimadzu, Japan) covered the range from 400-4000 cm-1. IR spectra of solid samples were detected using the KBr disc method. X-Ray Diffraction (XRD) (XRD-7000 Shimadzu, Japan) was utilized to determine crystalline structure of the prepared nanoparticles. EDX used to determine the elemental analysis.

\subsection{Catalytic Activity Test}

In a typical catalysis reaction, $25 \mathrm{mg}$ of catalysts sample (LDH-NS) or (A-LDH) was added to $10 \mathrm{~mL}$ of $25 \mathrm{mg} / \mathrm{L}$ of the dye solution in $50 \mathrm{~mL}$ glass beaker at room temperature. The degradation or decolorization of crystal violet was monitored by a UV/Visible spectrophotometer (Double beam) (T80+, PG instruments Ltd., UK.). At a maximum absorption $(\lambda=590 \mathrm{~nm})$ at different reaction periods. In another reaction, $300 \mu \mathrm{L}$ of hydrogen peroxide $\left(\mathrm{H}_{2} \mathrm{O}_{2}\right)$ was also added to the reaction mixture and repeated the experiment under the same reaction conditions. The same procedure was repeated up to 6 cycles for $(\mathrm{A}-\mathrm{LDH})$. The dye removal efficiency $(\mathrm{R} \%)$ is defined as:

$$
\mathbf{R} \%=\frac{\left(\mathbf{C}_{\mathbf{o}}-\mathrm{C}_{\mathbf{t}}\right)}{\mathbf{C}_{\mathbf{o}}} \times \mathbf{1 0 0}
$$

where, $\mathrm{C}_{\mathrm{o}}$ and $\mathrm{C}_{\mathrm{t}}$ are the initial concentration and the concentration of dye at time $\mathrm{t}$, respectively.

\subsection{Adsorption Kinetic}

\subsubsection{Pseudo first order kinetic model} $[22]$

The adsorption kinetics can be described by a pseudo- first order equation as suggested by Lagergren

$$
\log \left(\mathbf{q}_{\mathrm{e}}-\mathbf{q}_{\mathrm{t}}\right)=\log q_{e}+\frac{\mathrm{K}_{\mathrm{ads}} \mathrm{t}}{2.303}
$$

where, $\mathrm{q}_{\mathrm{e}}(\mathrm{mg} / \mathrm{g})$ is the amount of sorption at equilibrium time, $\mathrm{q}_{\mathrm{t}}(\mathrm{mg} / \mathrm{g})$ is amount of sorption at time and $K_{\text {ads }}\left(\mathrm{min}^{-1}\right)$ is the rate constant of pseudo first order sorption. The values of $K_{\text {ads }}$ were calculated from the slope of linear plots of $\log \left(q_{e}-q_{t}\right)$ versus $t$

$$
\mathbf{q}_{\mathrm{e}}=\frac{\left(\mathrm{C}_{\mathrm{o}}-\mathrm{C}_{\mathrm{e}}\right) \mathrm{V}}{1000 \mathrm{w}}
$$


where $\mathrm{C}_{\mathrm{o}}$ is the initial concentration $(\mathrm{mg} / \mathrm{L}), \mathrm{C}_{\mathrm{e}}$ is the dye concentration at equilibrium time intervals $(\mathrm{mg} / \mathrm{L}), \mathrm{V}$ is the volume of dye solution $(\mathrm{m} \mathrm{L})$ and $\mathrm{W}$ is the mass of adsorbent (g.)

$$
\mathbf{q}_{\mathbf{t}}=\frac{\left(\mathbf{C}_{\mathbf{o}}-\mathrm{C}_{\mathrm{t}}\right) \mathbf{v}}{1000 \mathrm{w}}
$$

where $\mathrm{C}_{\mathrm{t}}$ is the dye concentration at different time intervals $(\mathrm{mg} / \mathrm{L})$

\subsubsection{Pseudo second order kinetic model}

The pseudo second order equation developed by Ho and McKay [23] has a linear form as;

$$
\frac{t}{q_{t}}=\frac{1}{K_{2} q_{e}^{2}}+\frac{t}{q_{e}}
$$

where, $\mathrm{K}_{2}\left(\mathrm{~g} \mathrm{mg}^{-1} \mathrm{~min}^{-1}\right)$ is the rate constant of pseudo second order reaction.

\subsection{Catalytic Degradation Kinetic}

\subsubsection{First order kinetic model}

$$
\ln \frac{A_{\mathbf{o}}}{\mathrm{A}}=\mathrm{Kt}
$$

where, $\mathrm{A}_{\mathrm{o}}$ is the absorbance of $\mathrm{MB}$ at $\mathrm{t}=0, \mathrm{~A}$ is the absorbance of $\mathrm{MB}$ at different time intervals and $\mathrm{K}\left(\mathrm{s}^{-1}\right)$ is the apparent rate constant.

\section{Results and Discussion}

\subsection{Characterizing of Catalysts}

The morphology of as prepared Layer double hydroxide nanosheets (LDH NS) and (A-LDH) derived from alkali treatment is fully demonstrated in the SEM images at different magnification (Fig. 1a-c and Fig. 1d-h, respectively). From the images in Fig. 1a-h, it is clear that the morphology of the nanosheets does not vary before and after alkali etching with sheet size around $400 \mathrm{~nm}$ and the thickness about 40 $\mathrm{nm}$.
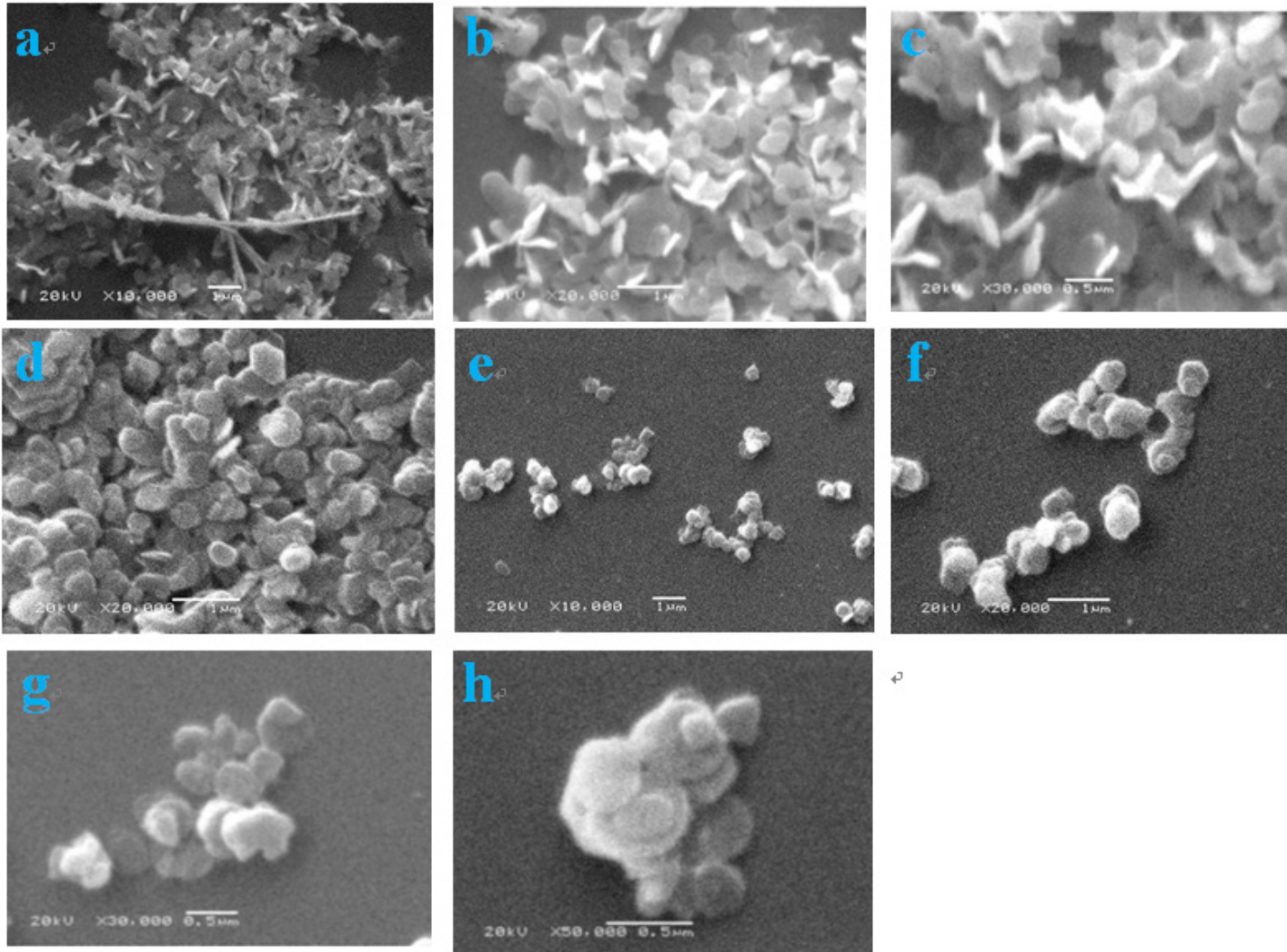

Figure 1. SEM images at various magnification for LDH NS (a-c) and A-LDH (d-h) 
The IR spectra are explained in Fig.2a, confirmed the presence of acetate ions in the both LDH NS and A-LDH. Consequently, at a higher wavenumber range, the broad absorption band at $3429 \mathrm{~cm}^{-1} \mathrm{was}^{-}$ due to the $\mathrm{O}-\mathrm{H}$ stretching vibration of the hydroxyl groups and water. The band located at $1634 \mathrm{~cm}^{-1}$ can be ascribed to the bending vibration of water. The carboxylate ions show absorption bands at 1560 $\mathrm{cm}^{-1}$ resulting from the antisymmetric $\mathrm{COO}^{-}$stretching vibration $\left(\mathrm{V}_{\mathrm{a}}\left(\mathrm{COO}^{-}\right)\right)[24]$. The absorption bands at $1345 \mathrm{~cm}^{-1}$ corresponded to the deformation modes of the methyl group [24]. At a lower wavenumber range, the bands assigned below $1000 \mathrm{~cm}^{-1}$ were due to lattice vibrations involving the metal-oxygen bonds. [1]. However, the bands at $1633 \mathrm{~cm}^{-1}$ and 1552 for LDH NS have a shift to 1641 $\mathrm{cm}^{-1}$ and $1533 \mathrm{~cm}^{-1}$, respectively.
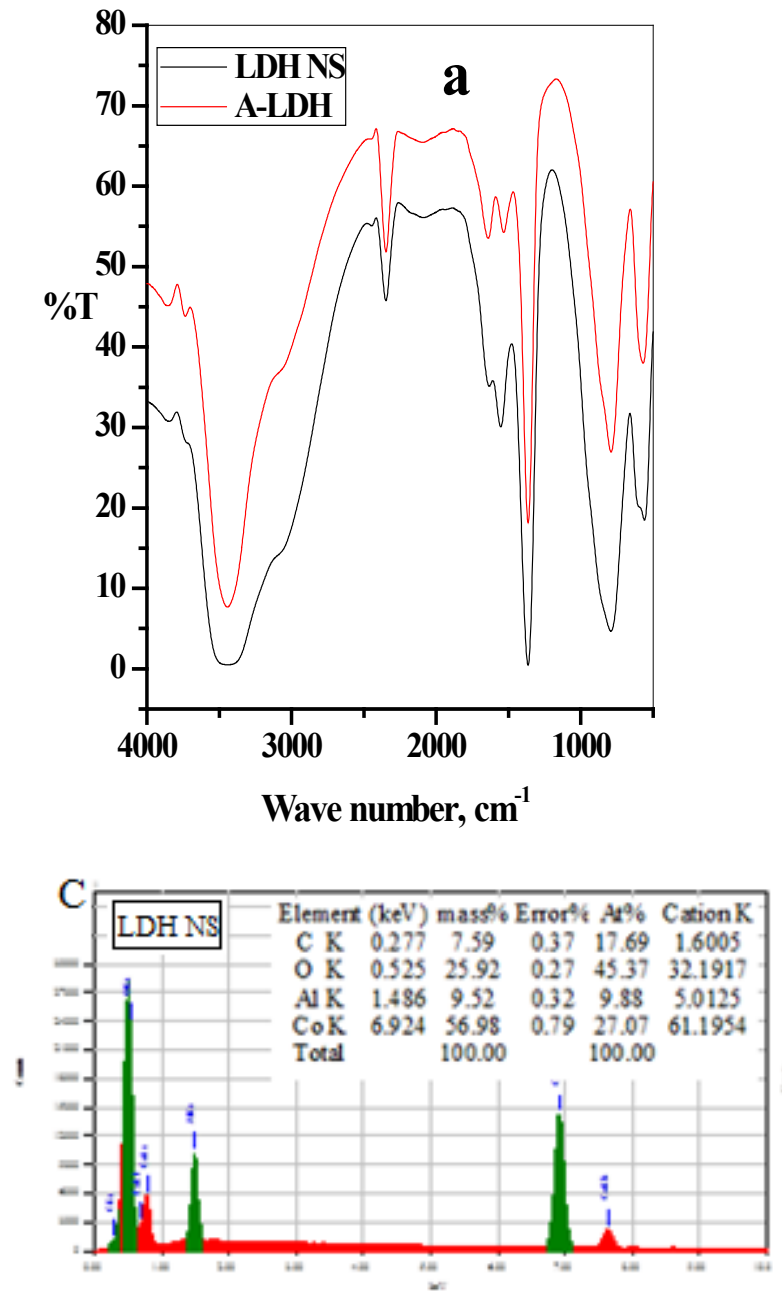
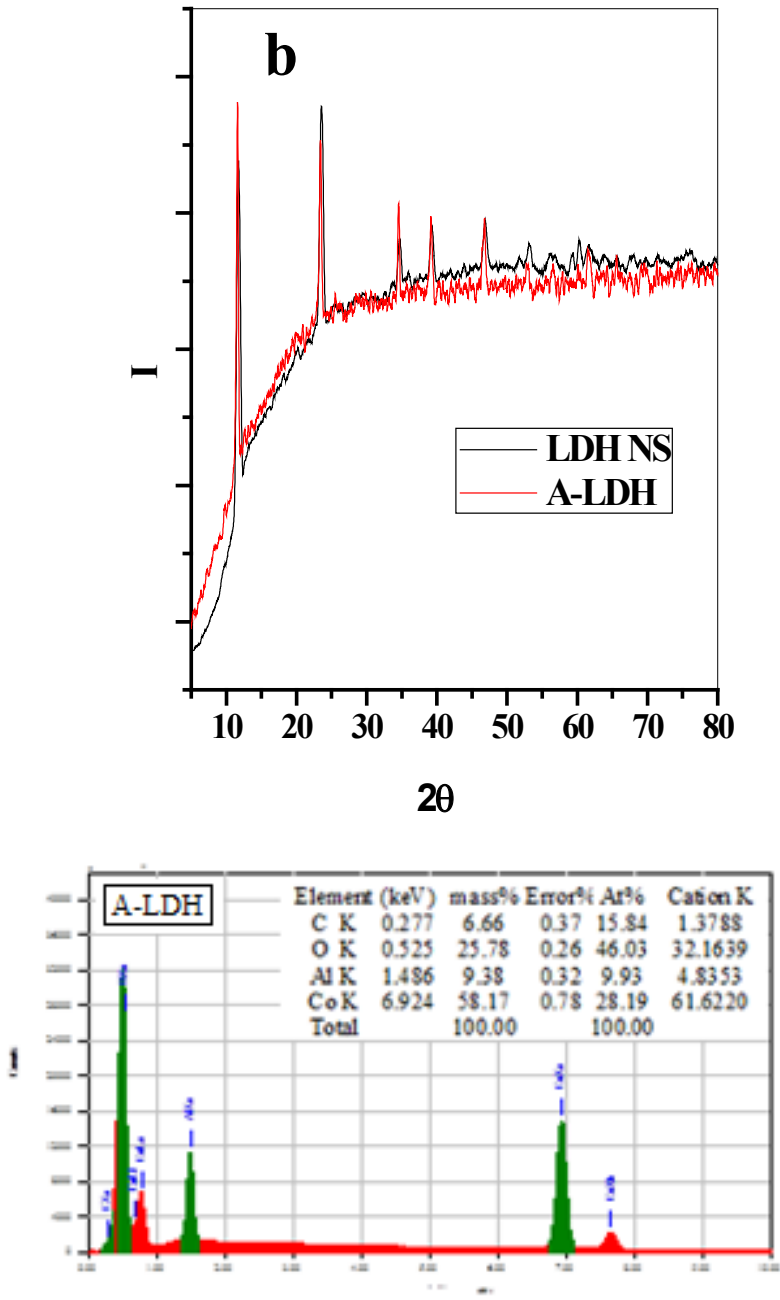

Fig. 2. a) FTIR, b) XRD and c) EDS analysis for LDH NS and A-LDH.

In contract, the broad band $3429 \mathrm{~cm}^{-1}$ (LDH NS) indicates the presence of intra and intermolecular Hbond between the surface ${ }^{-} \mathrm{OH}$ and chemisorbed water [25, 26]. A sharper peak at $3429 \mathrm{~cm}^{-1}$ (A-LDH) reveals to $\mathrm{H}$-bond free $\mathrm{OH}$ groups [26]. Moreover, the bending vibration peak for $\mathrm{H}-\mathrm{OH}$ is shown at 1641 $\mathrm{cm}^{-1}$ is more pronounced in the spectra of $(\mathrm{A}-\mathrm{LDH})$. This is may be leading to increase the activity of $(\mathrm{A}-\mathrm{LDH})$.

$\mathrm{XRD}$ is an essential tool for estimating the structure of LDHs. As shown in Fig. 2b, both Co-Al LDHs and A-LDHs exhibited the characteristic LDHs structure. The strong peaks at $2 \theta=11.8^{\circ}$ and $23.7^{\circ}$ correspond to (003) and (006) diffraction planes of LDHs [10], respectively. According to the Bragg equation, the basal distance was calculated to be $0.754 \mathrm{~nm}$ (for LDH Ns) and $0.764 \mathrm{~nm}$ (for A-LDH), indicating the presence of $\mathrm{CH}_{3} \mathrm{COO}^{-}$in the interlayer. The (003) diffraction peak for A-LDHs appears as much sharper and more intense compared with Co-Al LDHs, demonstrating a higher crystallinity. 
Additionally, according to Scherrer equation the A-LDHs has a crystal size bout $(\mathrm{d}=24.70 \mathrm{~nm})$ and Co-Al LDHs $(\mathrm{d}=13 \mathrm{~nm}$ ). Moreover, the molar ratio Co: $\mathrm{Al}$ is calculated 2.84 (A-LDHs) and 2.74 (Co$\mathrm{Al}$ LDHs) by elemental analysis using EDS, Fig. 2c.

\subsection{Catalytic activity of as Prepared Layers}
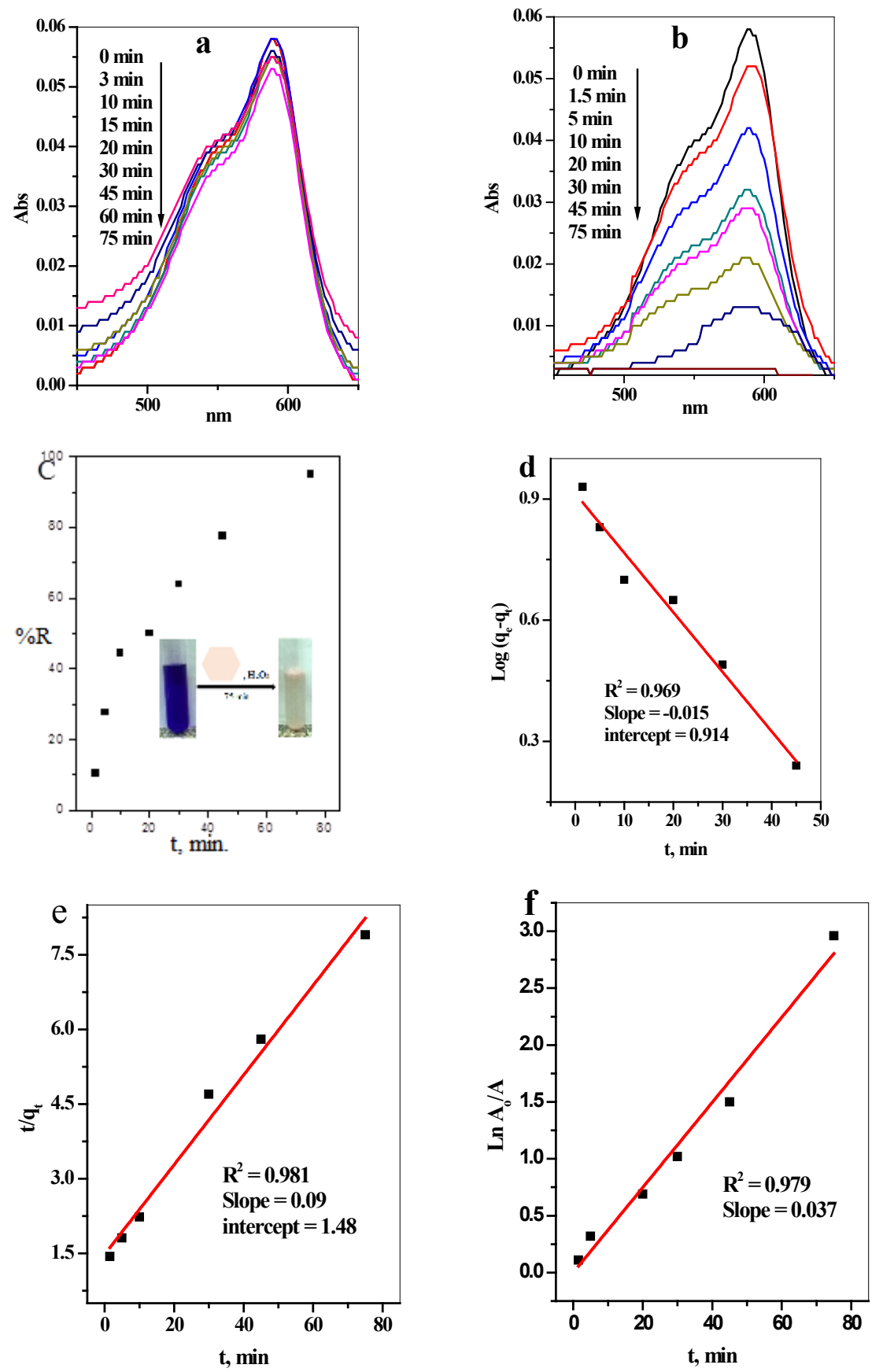

Figure 3. The UV-visible spectra CV solution in (a) absence and (b) presence of $\mathrm{H} 2 \mathrm{O} 2$, (c)effect of time on \%D of $\mathrm{CV}$, (d) pseudo first order model, (e) pseudo second order model and (f) effect of time on the reaction kinetic (LDH dose $=25 \mathrm{mg},[\mathrm{CV}]=25 \mathrm{mg} / \mathrm{L}$, dye solution volume $=10 \mathrm{ml}, \mathrm{T}=25 \mathrm{oC}$ )

The decolonization of the crystal violet (CV) dye is used for investigation of the activity for both LDH and A-LDH layer in the absence and the presence of $\mathrm{H}_{2} \mathrm{O}_{2}$ as assistant agent. The experimental results 
indicated that in the absence of $\mathrm{H}_{2} \mathrm{O}_{2}$ the activity of $\mathrm{LDH}$ towards the decolorization of $\mathrm{CV}$ is a manor (only $10 \%$ of the dye removed after 75 min.), as shown in Fig. 3a. While LDH layer shows high activity for $\mathrm{CV}$ decolonization in presence of $\mathrm{H}_{2} \mathrm{O}_{2}$, where, the $\mathrm{CV}$-dye completely removed within 75 min. (Fig. $3 \mathrm{~b}$ and 3c). However, the correlation coefficient $\left(\mathrm{R}^{2}\right)$ belonging to pseudo first order model is 0.969 as seen in Fig. 3d. While at applying the pseudo second Order model $R_{2}=0.981$, Fig. 3e. Moreover, the adsorption capacity $\left(q_{e}\right)$ calculated from the pseudo second order model is close to the value acquired from the experimental data, proving that the pseudo second order model as listed in Table1. The first order rate constant $(\mathrm{k})$ of the catalytic reaction was calculated from the slope of the linear relation of plotting Ln $\mathrm{A}_{\mathrm{o}} / \mathrm{A}$ vs $\mathrm{t}$ as seen in Fig.3f.
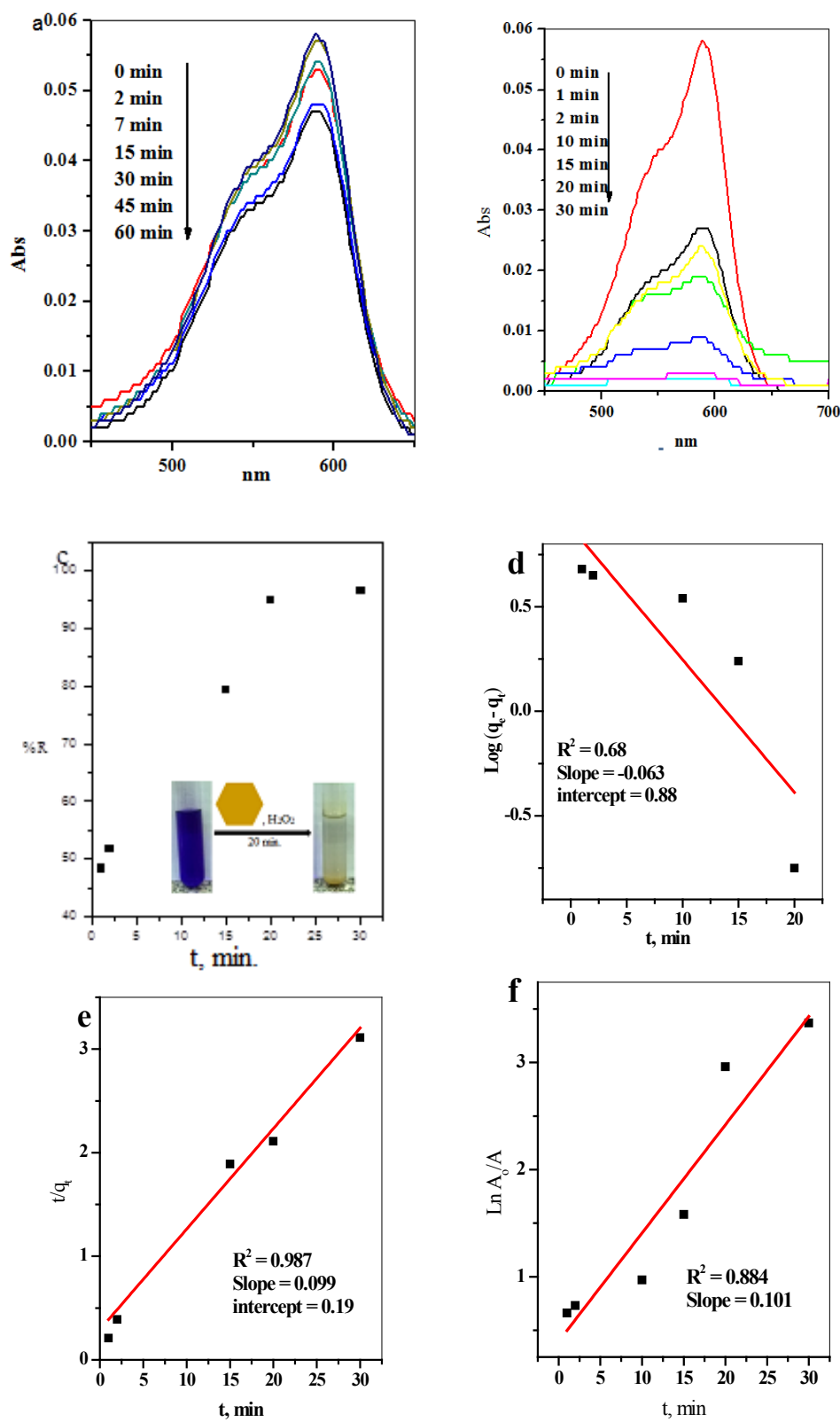

Figure 4. The UV-visible spectra CV solution in (a) absence and (b) presence of $\mathrm{H}_{2} \mathrm{O}_{2}$, (c)effect of time on $\% \mathrm{D}$ of $\mathrm{CV}$, (d) pseudo first order model, (e) pseudo second order model and (f) effect of time on the reaction kinetic (A$\mathrm{LDH}$ dose $=25 \mathrm{mg},[\mathrm{CV}]=25 \mathrm{mg} / \mathrm{L}$, dye solution volume $=10 \mathrm{ml}, \mathrm{T}=25{ }^{\circ} \mathrm{C}$ )

The UV-visible spectra (Fig. 4a-b) show that the decolrization of CV using CoO as a catalyst in the presence of $\mathrm{H}_{2} \mathrm{O}_{2}(\% \mathrm{D}=99.9)$ (Fig.4b) is highly efficient than that in the absence of $\mathrm{H}_{2} \mathrm{O}_{2}(\% \mathrm{R}=20.7)$ 
(Fig.4a) the color of the dye completely disappeared after 20 min. as seen in Fig.4c. The kinetic models pseudo first order model and pseudo second order model (Fig. 4d and 4e, respectively) were applied to the experimental data obtained. The results suggested that the pseudo second order model successfully describes the adsorption process with high R2 (0.987) better than pseudo first order model with low R2 (0.680). Moreover, qe acquired from the pseudo second order model is closer to the experimental values, implying that pseudo second order model is more applicable in this case, as recorded in Table 1.

Table1. Calculated parameters of the pseudo First-order and pseudo Second-order kinetic model

\begin{tabular}{ccccccccc}
\hline \multirow{2}{*}{ Solid dose, $\mathrm{g}$} & \multirow{2}{*}{$\mathrm{q}_{\mathrm{e} \text { exp }}(\mathrm{mg} / \mathrm{g})$} & \multicolumn{3}{c}{ First-order kinetic parameter } & & \multicolumn{3}{c}{ Second-order kinetic parameter } \\
\cline { 3 - 5 } & & $\mathrm{K}_{1}\left(\mathrm{~min}^{-1}\right)$ & $\mathrm{q}_{\mathrm{e} \text { cal }}(\mathrm{mg} / \mathrm{g})$ & $\mathrm{R}^{2}$ & & $\mathrm{~K}_{2}\left(\mathrm{~g} \mathrm{mg}^{-1} \mathrm{~min}^{-1}\right)$ & $\mathrm{q}_{\mathrm{e} \text { cal }}(\mathrm{mg} / \mathrm{g})$ & $\mathrm{R}^{2}$ \\
\hline LDH 0.025 & 9.48 & -0.035 & 8.2 & 0.969 & & 0.005 & 11.11 & 0.981 \\
A-LDH 0.025 & 9.66 & -0.15 & 7.6 & 0.680 & & 0.05 & 10.10 & 0.987 \\
\hline
\end{tabular}

Evidently, the A-LDH exhibits higher catalytic performance than LDH NS on CV degradation. This can be explained as; the degradation process of organic pollutants might proceed via an adsorptionoxidation-desorption process [27, 28]. Hence, the properties of the catalyst surface, especially surface hydroxyl groups, highly affected on the degradation of organic pollutants in heterogeneous catalytic reactions [29]. LDH has limited number of active sites due to H-bonded OH groups (refer to FTIR results), accordingly, the adsorption percent is limited $(\% \mathrm{R}=10)$. Moreover, the $\mathrm{H}_{2} \mathrm{O}_{2}$ molecule hardly contact with the LDH-surface due to the hindrance of H-bond network, consequently, the reaction time increase $(\mathrm{t}=60 \mathrm{~min})$ as illustrated in Fig. 5a. On the other hand, the presence of free $\mathrm{H}$-bond $\mathrm{OH}$ groups in A-LDH nanolayer increase the number of active sites available towards adsorption of CV dye $(\% \mathrm{R}=20.7)$. Moreover, the connection between the $\mathrm{H}_{2} \mathrm{O}_{2}$ molecule and A-LDH become more smoothing and as a result the reaction time reduced $(\mathrm{t}=20 \mathrm{~min})$ as detected in Fig.5b. In addition, the good crystallinity of A-LDH enhances its catalytic activity better than LDH, which is in good agreement with the result reported by Gao et al., 2014 [30], where he concluded that, the good crystalline MnOx shows a better catalytic activity than poor one.

\subsection{Reusability Properties}

The A-LDH was reused to decolorize the CV. The recycling experiments indicated that the $\mathrm{CoO}$ nanolayers have ability to remove about $99 \%$ of $\mathrm{CV}$ even after five-cycle runs of the degradation process, as shown in Fig.6a. However, the FTIR spectrum of the recycled CoO nanolayers in Fig. 6b, shows the same bands revealed to the unused $\mathrm{CoO}$ nanolayers, Fig.1d-h. Moreover, the morphology of the nanolayers after the treatment process was estimated by SEM. The SEM images in Fig. 6c-e, show that no changes are observed on the morphology of the used layer. This implies that these catalysis nanolayers are highly stable and can be reused.

\subsection{Mechanism Proposed for Catalytic Activity}

Based on the results obtained from the experimental data, $\mathrm{H}_{2} \mathrm{O}_{2}$ plays an important role in the catalytic reaction involving both CoAl-LDH and A-LDH as explained in Fig.7. The catalytic activity may have been expressed as in Eqs. (7-11). At first, CV species adsorbed on the catalyst surface to form intermediate complex (M-O-CV) Eq. (7) [29, 31]. The reactive oxygen species (ROS) as hydroxyl and perhydroxyl radicals ( $\mathrm{OH}$ and $\mathrm{OOH})$ were formed by addition of $\mathrm{H}_{2} \mathrm{O}_{2}$ to the catalyst [32, 7] Eqs. 8 and 9. Finally, the adsorbed CV was decomposed by the produced reactive oxygen species Eqs. 10 and 11.

$$
\begin{gathered}
\mathrm{M}-\mathrm{OH}+\mathrm{CV}-\mathrm{Cl} \rightarrow \mathrm{M}-\mathrm{O}-\mathrm{CV}+\mathrm{HCl} \\
\mathrm{M}(\mathrm{II})+\mathrm{H}_{2} \mathrm{O}_{2} \rightarrow \mathrm{M}(\mathrm{III})+{ }^{\cdot} \mathrm{OH}+{ }^{-} \mathrm{OH} \\
\mathrm{M}(\mathrm{III})+\mathrm{H}_{2} \mathrm{O}_{2} \rightarrow \mathrm{M}(\mathrm{II})+{ }^{\cdot} \mathrm{OOH}+{ }^{+} \mathrm{H} \\
\mathrm{M}-\mathrm{O}-\mathrm{CV}+{ }^{\cdot} \mathrm{OH} \rightarrow \mathrm{CO}_{2}+\mathrm{H}_{2} \mathrm{O} \\
\mathrm{M}-\mathrm{O}-\mathrm{CV}+{ }^{\cdot} \mathrm{OOH} \rightarrow \mathrm{CO}_{2}+\mathrm{H}_{2} \mathrm{O}
\end{gathered}
$$



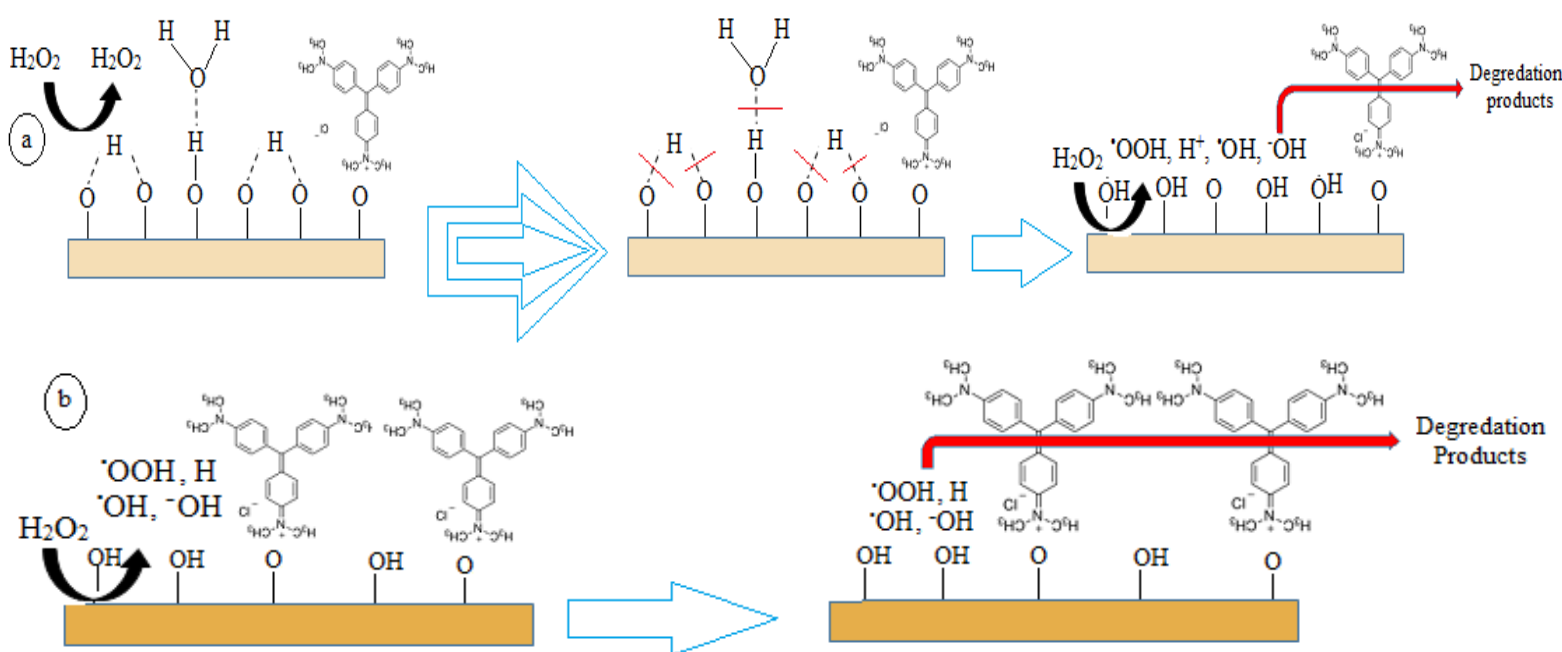

Figure 5. Schematic diagram explain the effect of H-bond on the catalytic behavior of a) LDH NS and b) A-LDH
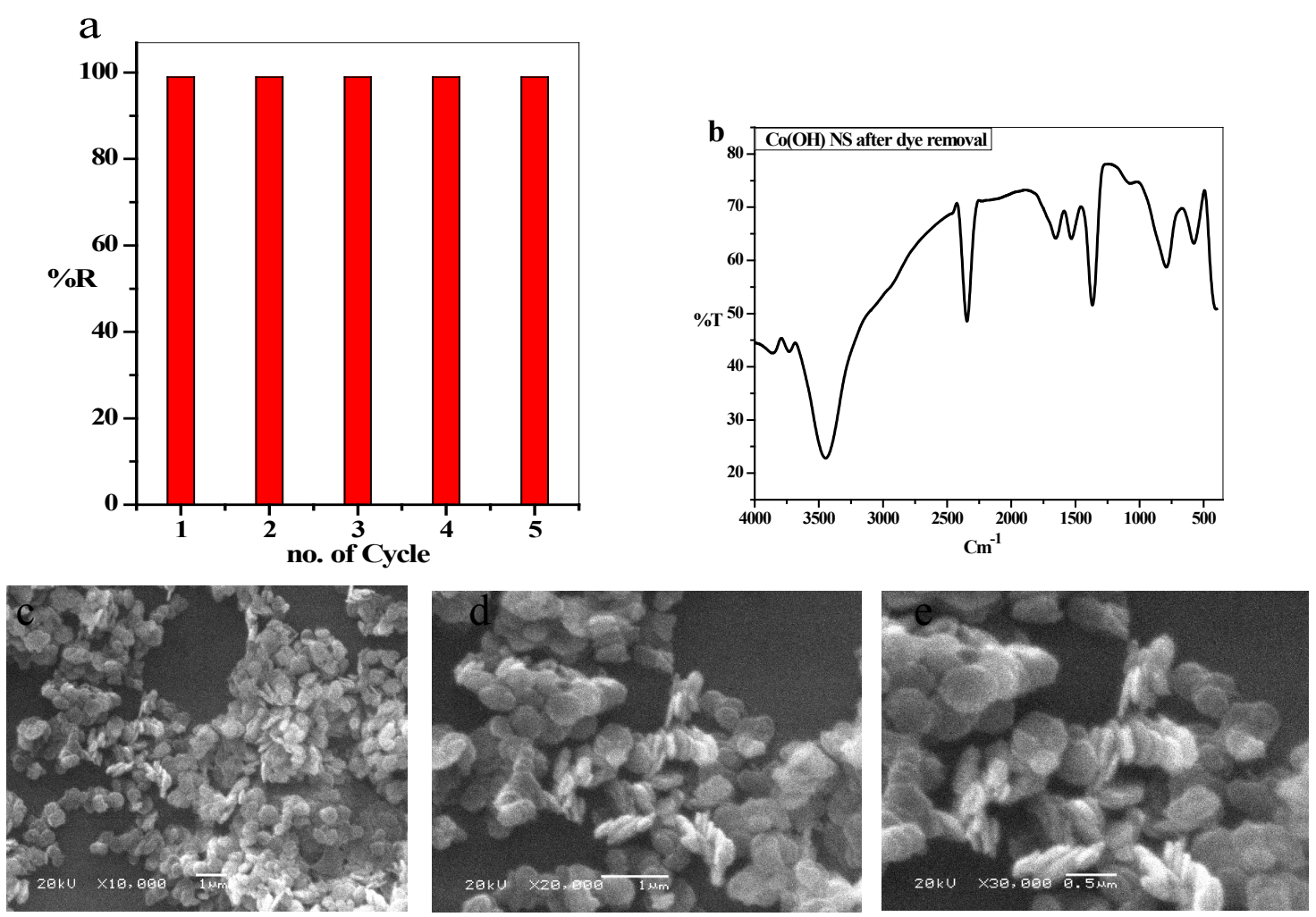

Figure 6. a) The reusability curve of the catalyst $\mathrm{Co}(\mathrm{OH})$-NS for 5 times used, b) FTIR-spectrum of the used catalyst $\mathrm{Co}(\mathrm{OH})-\mathrm{NS}$, c-e) SEM images at different magnification of the used catalyst $\mathrm{Co}(\mathrm{OH})-\mathrm{NS}$ 


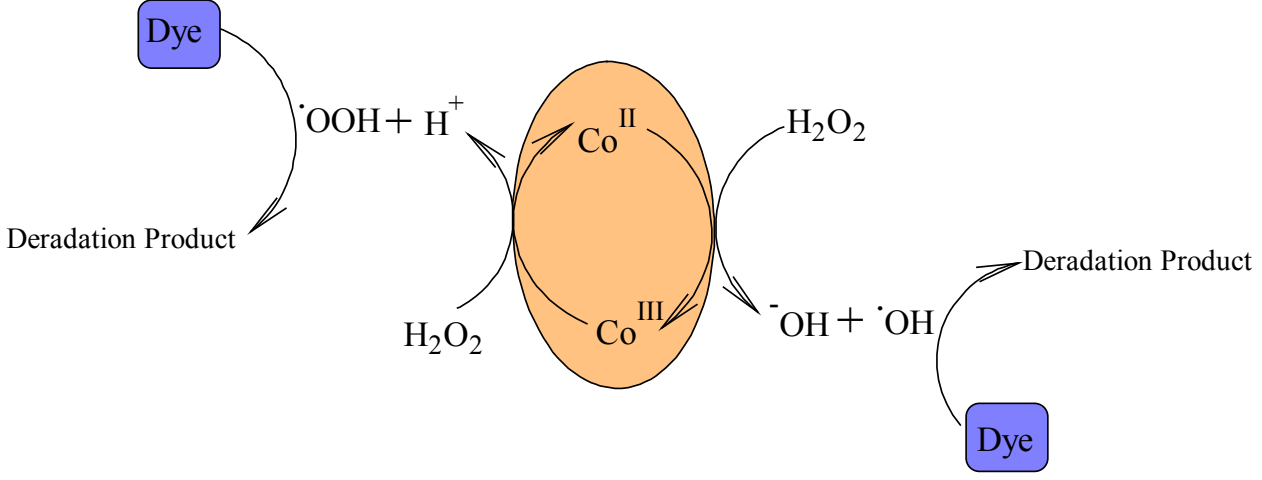

Figure 7. Schematic diagram shows the formation of (ROS) and the dye degradation.

\section{Conclusion}

In summary, we reported a simple approach for synthesis of A-LDH by alkali treatment of CoAl-LDH. The two samples CoAl-LDH and A-LDH show high catalytic efficiency for CV degradation in the presence of $\mathrm{H}_{2} \mathrm{O}_{2}$, this efficiency is highly diminished in absence of $\mathrm{H}_{2} \mathrm{O}_{2}$. The degradation reaction in case of A-LDH requires about $1 / 4$ of the time in case of CoAl-LDH. This indicates that in our case, the alkali etching enhances the catalytic efficiency.

\section{Reference}

1. S. Zhu, S. Jiao, Z. Liu, G. Pang, S. Feng, High adsorption capacity for dye removal by CuZn hydroxyl double salts, Environmental Science: Nano, vol. 1, pp. 172-180, 2014.

2. Z. M. Ni, S. J. Xia, L. G. Wang, F. F. Xing, G. X. Pan, Treatment of methyl orange by calcined layered double hydroxides in aqueous solution: Adsorption property and kinetic studies, Journal of Colloid Interface Science, vol. 316, pp. 284-291, 2007.

3. Z. Xiong, L. L. Zhang, J. Ma, X. S. Zhao, Photocatalytic degradation of dyes over graphene-gold nanocomposites under visible light irradiation, Chemical Communications, Vol. 46, pp. 6099-6101, 2010.

4. Y. C. Sharma, Uma, S. N. Upadhyay, Removal of a Cationic Dye from Wastewaters by Adsorption on Activated Carbon Developed from Coconut Coir, Energy Fuels, Vol. 23, pp. 2983-2988, 2009.

5. R. Khan, U. Banerjee, in Biodegradation of Azo Dyes, ed. H. Atacag Erkurt, Springer, Berlin Heidelberg, 73-84, 2010 .

6. S. Prakash, A. M. Rajesh and V. K. Shahi, Chlorine-tolerant poly electrolyte membrane for electrochemical dye degradation, Chemical Engineering Journal, vol. 168, 108-114, 2011.

7. S. Hsieh, P-Y. Lin, FePt nanoparticles as heterogeneous Fenton-like catalysts for hydrogen peroxide decomposition and the decolorization of methylene blue, Journal of Nanoparticles Research, vol. 14, 956, 2012.

8. M. Stoyanova, S. Christoskova, Catalytic degradation of methylene blue in aqueous solutions over Ni- and Cooxide systems, Center European Journal of Chemistry, Vol. 9, no. 6, pp. 1000-1007, 2011.

9. Q. Tao, J. Zhu, R. L. Frost, T. E. Bostrom, R. M. Wellard, J. Wei, P. Yuan, H. He, Silylation of layered double hydroxides via a calcination-rehydration route. Langmuir, Vol. 26, pp. 2769-2773, 2010.

10. S. Huang, G-N Zhu, C. Zhang, W. W. Tjiu, Y-Y Xia, T. Liu, Immobilization of Co-Al Layered Double Hydroxides on Graphene Oxide Nanosheets: Growth Mechanism and Supercapacitor Studies, ACS Applied Material Interfaces, vol. 4, pp. 2242-2249, 2012.

11. Z. P. Xu, Q. H. Zeng, G. Q. Lu and A. B. Yu, Inorganic nanoparticles as carriers for efficient cellular delivery, Chem. Eng. Sci., vol. 61, pp. 1027-1040, 2006.

12. C. Mousty, Sensors and biosensors based on clay-modified electrodes - new trends, Appl. Clay Sci., vol. 27, pp. 159-177, 2004.

13. K. H. Goh, T. T. Lim and Z. Dong, Application of layered double hydroxides for removal of oxyanions: a review, Water Res., vol. 42, pp. 1343-1368, 2008. 
14. B. F. Sels, D. E. De Vos and P. A. Jacobs, Hydrotalcite-like anionic clays in catalytic organic reactions, Catal. Rev.: Sci. Eng., vol. 43, pp. 443-4882001.

15. T. Stimpfling and F. Leroux, Supercapacitor-Type Behavior of Carbon Composite and Replica Obtained from Hybrid Layered Double Hydroxide Active Container, Chem. Mater., vol. 22, pp. 974-987, 2010.

16. Z.P. Diao, Y. X. Zhang, X. D. Hao, Z. Q. Wen, Facile synthesis of CoAl-LDH $/ \mathrm{MnO}_{2}$ hierarchical nanocomposites for high-performance supercapacitors, Ceram. Internat. Vol. 40, pp. 2115-2120, 2014.

17. J. Fang, M. Li, Q. Li, W. Zhang, Qi. Shou, F. Liu, X. Zhang, J. Cheng, Microwave-assisted synthesis of CoAllayered double hydroxide/graphene oxide composite and its application in supercapacitors, Electrochimica Acta, vol. 85, pp. 248-255, 2012.

18. P. Guoxiang, X. Xinhui, L. Jingshan, C. Feng, Y. Zhihong, F. Hongjin, Preparation of CoAl layered double hydroxide nanoflake arrays and their high supercapacitance performance, Appl. Clay Sci., Vol. 102, pp. 28-32, 2014.

19. S. Wang, Z. Huang, R. Li, X. Zheng, F. Lu, T. He, Template-assisted synthesis of NiP@CoAl-LDH nanotube arrays with superior electrochemical performance for supercapacitors, Electrochimica Acta, vol. 204, pp. 160-168, 2016.

20. M. Bellotto, B. Rebours, O. Clause, J. Lynch, D. Bazin, E. Elkaim, Decomposition Mechanism: A Clue to the Structure and Reactivity of Spinel-like Mixed Oxides, Journal of Physical Chemistry, vol. 100, pp.8535-8542, 1996.

21. H. Schaper, J. J. Berg-Slot, W. H. J. Stork, Stabilized magnesia: A novel catalyst (support) material, Applied Catalysis, vol. 54, pp. 79-90, 1989.

22. S. Lagergren, About the theory of so called adsorption of soluble substances. K. Sven. Vetenskapsakad. Handlingar Band, vol. 24, pp.1 - 39, 1898.

23. Y.S. Ho and G. McKay, The sorption of lead (II) ions on peat, Water Reseaarch, vol. 33, pp. 578 - 584, 1999.

24. A.S. Milev, G. S. K. Kannangara, M. A. Wilson, Template-Directed Synthesis of Hydroxyapatite from a Lamellar Phosphonate Precursor, Langmuir, vol. 20, pp.1888-1894, 2004.

25. S. Abbasizadeh, A. R. Keshtkar, M. A. Mousavian, Preparation of a novel electrospun polyvinyl alcohol/titanium oxide nanofiber adsorbent modified with mercapto groups for uranium(VI) and thorium(IV) removal from aqueous solution, Chemical Engineering Journal, vol. 220, pp. 161-171, 2013.

26. S. R. Kamath, A. Proctor, Silica Gel from Rice Hull Ash: Preparation and Characterization, Cereal Chemistry, Vol. 75, no. 4, 484-487, 1998.

27. F. Li, J. Wu, Q. Qin, Z. Li, X. Huang, Facile synthesis of $\gamma$-MnOOH micro/nanorods and their conversion to $\beta$ $\mathrm{MnO}_{2}, \mathrm{Mn}_{3} \mathrm{O}_{4}$, Journal of Alloy Compdound, vol. 492, pp. 339-346, 2010.

28. C. Yu, G. Li, L. Wei, Q. Fan, Q. Shu, J.C. Yu, Fabrication, characterization of $\beta-\mathrm{MnO}_{2}$ microrod catalysts and their performance in rapid degradation of dyes of high concentration, Catalysis Today, vol. 224, pp. 154, 2014.

29. S. Xing, Z. Zhou, Z. Ma, Y. Wu, Characterization and reactivity of $\mathrm{Fe}_{3} \mathrm{O}_{4} / \mathrm{FeMnO}_{\mathrm{x}}$ core/shell nanoparticles for methylene blue discoloration with $\mathrm{H}_{2} \mathrm{O}_{2}$, Applied Catalysis B: Environment, vol. 107, pp.386- 392, 2011.

30. G. Cheng, L. Yu, T. Lin, R. Yang, M. Sun, B. Lan, L. Yang, F. Deng, A facile one-pot hydrothermal synthesis of $\beta-\mathrm{MnO}_{2}$ nanopincers and their catalytic degradation of methylene blue, Journal of Solid State Chemistey, vol. 217, pp. 57-63, 2014.

31. M. Abbas, R. B. Parvatheeswara, V. Reddy, C. G. Kim, $\mathrm{Fe}_{3} \mathrm{O}_{4} / \mathrm{TiO}_{2}$ core/shell nanocubes: Single-batch surfactantless synthesis, characterization and efficient catalysts for methylene blue degradation, Ceramic International, vol. 40, pp.11177-11186, 2014

32. S.K. Ling, S. Wang, Y. Peng, Oxidative degradation of dyes in water using $\mathrm{Co}^{2+} / \mathrm{H}_{2} \mathrm{O}_{2}$ and $\mathrm{Co}^{2+}$ /peroxymonosulfate, Journal of Hazardous Materials, vol. 178, pp. 385-389, 2010.,

33. S. Hsieh, P-Y. Lin, FePt nanoparticles as heterogeneous Fenton-like catalysts for hydrogen peroxide decomposition and the decolorization of methylene blue, Journal of Nanoparticles Research, vol. 14, 956, 2012. 